Journal of Contemporary Educational Research

Research Article

\title{
Research on the Application of Hybrid Teaching in Automobile Major Teaching in Colleges and Universities
}

\author{
Chunfeng Wang \\ East University of Heilongjiang, China
}

Funding: Core courses of Heilongjiang Oriental University(1810405).

\begin{abstract}
Due to the novel coronavirus pneumonia epidemic, online education has become an inevitable choice for universities to carry out teaching. In this paper, in order to solve the problems encountered during automobile major, we adopt the network platform to mix online education mode, to provide students with timely and accurate learning mode. This paper aims to help students to have positive learning motivation, have good learning experience and improve their learning effect.
\end{abstract}

Key words: Mixed teaching; Colleges and universities; Automobile Major

Publication date: October, 2020

Publication online: 31 October, 2020

*Corresponding author: Chunfeng Wang, 283034044@ qq.com

Novel coronavirus pneumonia is a new way to promote the development of information technology education in China. Considering the impact of new coronavirus pneumonia, online education has become an inevitable choice for universities to suspend classes. In addition, the blended education design allows online and offline education to complement and promote each other, so as to optimize the curriculum and improve the training effect. As a result, the mixed education model has gradually entered the vision of educators, and many domestic experts have begun to devote themselves to the research of mixed education mode. Novel coronavirus pneumonia is a major opportunity for blended education in the special environment of "new online pneumonia". In the present education, the idea and method of education should be reformed and innovated. It provides practical experience for the organic combination of classroom and online education in the post era. Based on this, this paper integrates traditional classroom training and practical experience with network information technology, constructs a professional and highly feasible new university classroom, and how to find a convenient, efficient, attractive and popular mixed education mode.

\section{Definition of core concepts}

\subsection{Blended teaching}

Mixed education originated from American corporate education. By organically combining traditional offline education with online education, the company can improve its economic benefits and educational efficiency. Based on these improvements, we are introducing this kind of mixed education model to enhance the learning effect in the field of education. In foreign countries, there are applications such as blended learning and blended teaching. After years of theoretical research and teaching practice, domestic experts and scholars have defined blended education from different perspectives, which can be summarized into three types. One is to start with learning methods and methods that are considered new learning methods, and the other is from education. From the perspective of media, it is considered as the integration of media elements, and the third is considered as the combination of several activities in event design.

\subsection{Definition of Blended Teaching in China}

He Kekang, Professor of Beijing Normal University, 
believes that blended education combines the advantages of traditional learning methods with the advantages of digital or online learning, and adopts a real "student-centered, teacher led" education model. In this teaching mode, teachers are mainly responsible for organization, supervision, control, support and guidance, while students can learn freely and independently in the mixed learning environment created by teachers online and offline. Professor Li Jiaobao of Shanghai Normal University focuses on the optimal combination of educational media, teaching methods and teaching strategies when defining the mixed education mode. He believes that "mixed teaching method" refers to the realization of "comprehensive teaching method" through the rational use of teaching media, methods and Strategies of teachers and students in teaching practice, so as to optimize teaching and promote students' selfstudy.

\subsection{Definition of foreign blended teaching}

American Association for training and development Singh and Reid use five "appropriate" methods to illustrate the concept of blended education. It means using the right skills at the right time, combining the right learning style with the right direction. To provide learners with appropriate skills, in a learning way to optimize the learning effect. American Training Association believes that blended education is a teaching method, which is the best personalized display of business and performance objectives, optimized learning methods and learning content. India's NIIT proposed in the white paper on blended learning that blended education is a face-to-face real-time online learning and self-paced teaching method. In most cases, it is also used to describe a mix of media, guidance and technology.

\section{Teaching technology environment and platform}

Because online learning requires students to have higher self-learning ability and self-discipline ability, some students with weak self-control are easy to have students whose learning tasks are not clear and end hastily. Therefore, it is necessary to reduce the negative effects of technical means. If the video is too long or lacks animation, it will be difficult for students to continue to focus, and because the comprehensive automobile fault diagnosis process is very professional and practical, students with insufficient understanding will not be able to complete the learning objectives.

Therefore, the choice of online education and lecture platform is particularly important, we must make full use of information technology to improve the efficiency of education. Choose to use "Tencent conference live platform" to explain the key points and difficulties of teaching according to the rhythm of students, so as to realize communication at any time, answer questions and quickly understand students' mastery. Use "MOOC teaching platform" to draw a special label suitable for students' personal learning. It also provides an educational environment for hands-on thinking in teaching, which provides the functions of interaction between teachers and students, analysis of learning process data, and timely understanding of students' learning dynamics; Use wechat platform to release reminders, learning instructions, etc., so that students can understand their learning needs at any time.

There are three main functional modules among them: Cloud training, cloud learning and cloud management. (1) Cloud education. Teachers can obtain and share high-quality education resources, prepare courses easily and efficiently, interact with students in-depth classroom training, obtain feedback on students' learning effect and timely optimize teaching requirements. (2)Cloud learning. It meets the needs of students to obtain course information, enables students to study independently and cooperatively, exchange and share learning, and timely receive feedback on learning effect and teaching guidance. (3)Cloud management. In order to meet the management needs of various managers, training management based on various situations is realized. "Cloud course" mainly includes functional modules, such as teacher performance, resources, members, activities, messages, details, etc.

\section{High quality teaching resources}

Teaching content is the primary factor to ensure the quality of lectures. Rich and diverse speech materials can vividly express the content of the speech. There are two types of handouts: Second development and utilization of materials and self built materials. Many high-quality online courses are free and open to help students learn online. The development and utilization of secondary resources adopts the " $1+\mathrm{X}$ " format, combined with the academic conditions and characteristics of the education platform for screening, transformation, and integration. In the course content related to MOOC, intelligent vocational education and 
other resource platforms of China University; Students can complete the test and study by choosing their own courses. Finally, the smart vocational education resource library provides one of the best online courses, and selects $\mathrm{x}$ high-quality chapters of undergraduate courses to maximize the use of high-quality online resources. You need to be able to focus on using the technology platform without falling into a technology blind spot, and you'll be stuck with the lack of online learning itself. At the same time, we will actively explore the ideological and political education content of the course by using relevant resources, such as learning epidemic prevention knowledge.

In order to better understand teaching strategies, it is very important to design, research and analyze the initial ability of teaching subjects in the key links of teaching activities and evaluation methods. Therefore, before the teaching of this course, this paper conducted a questionnaire survey on the learning methods of educational themes. Through the questionnaire star wechat APP, 46 questionnaires were distributed to students, and 46 questionnaires were returned. The recovery rate was $100 \%$, and the effective rate was $100 \%$.

The survey results show that: Most students usually study through classroom and mobile phone, while a few students usually study through books and computers. This shows that students' current learning methods have been diversified. There are traditional classroom learning and online learning. The survey found that $71.74 \%$ of the students mainly use mobile phones for learning, which indicates that they may seek to reform the education mode based on mobile devices such as mobile phones.

\section{Development and key points of teaching design}

\subsection{Design of mixed teaching implementation model}

Based on the "cloud class" online education platform, this paper establishes a mixed education implementation model of automobile application and maintenance "automobile engine management system inspection and repair" course in secondary vocational schools. The purpose of this model is to maximize the benefits of online and offline education, increase students' interest in learning, and improve learning effect. The overall structure of the model is illustrated by taking the course of automobile engine management system inspection and repair in secondary vocational education as an example. Based on the school's mixed education environment, the cloud course online education platform "automobile engine management system inspection and repair" combines the platform functions based on the reasonable analysis of education objectives, education contents, education materials and education objectives. "Inspection and repair of automobile engine management system" carries out online education activities, prepares relevant education resources, observes students' learning path in real time, and records them in the form of "experience value" as the evaluation standard.

The introduction of the concept of "flipped classroom" education, building a bridge between online education mode and offline education mode, can well connect online education and offline education, realize the diversification of online education and education resources, and the ability to start learning anytime and anywhere. According to the location constraints, students can adjust their learning according to their ability, the latest knowledge and information It will not affect the face-to-face communication between teachers and students through offline education, nor will it affect the greater interaction between students and teachers. You can take advantage of the advantages of making it faster. As a powerful and relatively diversified teaching mode, teachers can adjust the teaching content according to the current situation of students in the class or the advantages of flexible teaching.

\subsection{Design of teaching activities and preparation of teaching resources}

Teaching activities usually refer to classroom teaching activities, which are the unit of classroom teaching and the basic form of school education. Educational activities are a complete educational system composed of interrelated and linked links. Training links usually include six links: Review, new curriculum introduction, new curriculum, teacher-student interaction, class summary and assignment. Due to the diversity of teachers, educational connections are also changing and not all tasks need to be covered. Each link is used in the classroom, but the design of educational activities directly determines the effectiveness of education and ensures the development of education. Based on the research on the hybrid teaching mode of "cloud class" online teaching platform, the design of teaching activities is divided into three stagesbefore, during and 
after class.

\subsubsection{Design before class}

The design of pre class education activities is mainly based on the online activities of "cloud class" online education platform. The main content of the teacher is to upload the designed and organized resources (video, courseware, file, test, etc). In "cloud classroom", most of the contents are basic knowledge points, and important and difficult knowledge and skills are mainly completed in offline lectures. We will inform students about the "cloud course" and the pre class homework of the class wechat group. Students complete appropriate preparation and gain experience. Teachers can check students' learning progress behind the scenes of "cloud class", supervise and remind students in progress, and use artificial intelligence virtual robot to monitor students' different performances and obtain accurate and personalized guidance. Meanwhile, teachers can track each student's learning path and unfinished students and remind them.

\subsubsection{Classroom design}

The design of classroom teaching activities involves two aspects online and offline. The design of classroom online education activities is based on the "activities" and "classroom results" of the "cloud curriculum" functional module. According to the different educational objectives, the corresponding voting questionnaire, brainstorming, group cooperation and other educational activities were randomly designed. Organize students to participate in classroom teaching activities, such as selecting people, raising hands, conducting group assessment, etc., in order to improve students' interest in learning and participating in the classroom, and achieve the educational objectives. In the design of offline teaching activities, this paper combines the six level teaching links with the "six steps" commonly used in vocational education, so that students can easily obtain teaching knowledge in the process of practice through task-oriented method. At the same time, through group discussion, the team cooperation ability of the students is improved to realize the emotion, attitude and value goal of the education goal.

\subsubsection{After class design}

The design of extracurricular education activities is relatively simple, mainly through online completion. The teacher arranges this assignment and provides learning materials, completes the classroom activities, completes the teacher evaluation and student mutual evaluation, and checks the overall learning situation and learning path of each student through the "member" function. Due to the lack of self-control skills, teachers are required to guide, respond and supervise students in all aspects.

\subsection{Key points in the blended teaching process}

\subsubsection{Help students solve their difficulties on time}

For the students who are just beginning to receive mixed education, there will inevitably be various problems in the learning process. Teachers must help students solve the difficulties in the learning process in time, so that all students can participate in all aspects of education seamlessly and improve the efficiency of education.

\subsubsection{Make full use of the leading role of teachers}

The teaching process in the mixed teaching method is a joint activity process between teachers and students, which is a learning process under the guidance of teachers. In the teaching process, teachers can control the whole mixed teaching process and track the teaching progress according to the situation of students. Through online learning data, it analyzes the learning status of each learner, finds out the key points and difficulties of teaching, and then through in-depth communication and explanation with students in offline courses, it promotes the internalization of students' online independent learning knowledge.

\subsubsection{Reasonable use of the combination of online learning and offline learning}

The mixed education model puts forward higher requirements on how to reasonably design online and offline course content and educational activities. In the implementation of blended education combining online autonomous learning and offline classroom education, teachers need to carefully consider the hybrid method and mixing time, because the transfer of theoretical knowledge should also pay attention to improving students' collaborative ability and practical skills.

\section{Conclusion}

Through secondary development and utilization of high-quality online education resources, online learning provides students with rich learning resources. Mixed network education provides students with timely and 
accurate learning support and learning evaluation, and makes enough time and space for students' independent design. In the teaching process, the whole process of dynamic evaluation is used to generate positive learning motivation, good learning experience and improve learning effect, which can effectively improve and enhance students' learning enthusiasm and initiative.

\section{References}

[1] Zhou YQ. Application of hybrid teaching mode based on flipped classroom in automobile professional English Teaching [J]. Writer's world, 2020(16): $41+43$.

[2] Wang H. Exploration of online live hybrid teaching mode based on Resource Library -- Taking the new energy vehicle technology major of electromechanical automobile College as an example [J]. Information system engineering, 2020(5): 169170.

[3] Xu ZY, Jiang LL, Zhu SZ. Exploring the reform practice of teaching mode of new energy automobile specialty based on the trend of information technology application [J]. Information system engineering, 2020(4): 164-165.

[4] Fan LH, Lin SC, Liu WL. Application of hybrid teaching mode based on network teaching platform in Higher Vocational automobile professional teaching -- Taking the course of automobile chassis construction and maintenance as an example [J]. Light industry technology, 2019, 35(9): 162-164 + 166.

[5] Tian FX. Exploration and practice of Hybrid Teaching in automobile marketing classroom teaching $[\mathrm{J}]$. Automobile maintenance and repair, 2019 (06): 46-48.

[6] Li FY, Zhao CL. OBE concept guides teaching reform practice of automotive service engineering $[\mathrm{J}]$. Science and technology perspective, 2018(36): 102-103. 